\title{
EL CONTRATO DE SERVICIOS EN EL CODIGO CIVIL Y COMERCIAL ¿UNA REGULACION PROGRESIVA PARA EL DERECHO DEL TRABAJO?
}

\section{Ricardo León Chércoles ${ }^{1}$}

Sumario: I. Introducción. II. La regulación del contrato de servicios en el Código Civil y Comercial. III. Los puntos de contacto entre la relación de trabajo y el contrato de servicios. IV. Posibles avances de la regulación del contrato del servicios sobre el Derecho del Trabajo, desde una posición crítica. V. La regulación del contrato de servicios en el Código Civil y Comercial es progresiva. VI. Los criterios desde la legislación del trabajo y la necesaria aplicación de las normas del CCyC sólo en caso de recurrir a la presunción del art. 23 de la LCT. VII. Criterios de la regulación del contrato de servicios útiles a los fines de desvirtuar o revalidar la presunción del art. 23 de la LCT. VIII ¿Una revalorización del contrato de servicios frente a la relación de trabajo? A raíz de los fallos "Cairone" y "Rica" de la CSJN. IX. La renovación de los indicadores de laboralidad a raíz de las trasformaciones tecnológicas en el ámbito de los servicios. X. La relación de trabajo y el contrato de servicios a la luz de la Recomendación 198 de la OIT. XI. Algunos pasos se han dado y otros se han propuesto. XII. La protección del trabajo con independencia de su forma de realización y la consiguiente desaparición de los límites entre la relación de trabajo dependiente y el contrato de servicios. XIII. Bibliografía por autor.

Resumen: La regulación del contrato de servicios en nuestro CCyC, que a nuestro modo de ver es progresiva, posee significativa relevancia a la hora de determinar si nos encontramos frente a una relación de trabajo dependiente o frente al citado contrato, máxime, cuando en el caso concreto pudiera resultar aplicable la presunción establecida en el art. 23 de la LCT, puesto que en tal supuesto serán los criterios del contrato de servicios los que habrá que tener en cuenta a los fines de desvirtuar o no la citada presunción.

Palabras clave: Relación. Contrato. Presunción. Recomendación. Indicadores

\footnotetext{
1 Abogado laboralista (UNC). Doctorando en derecho (UNC). Especialista en Derecho del Trabajo y la Seguridad Social (UNC - UCC - UNL). Profesor de post grado de Carreras de Especialización y Diplomaturas en Derecho del Trabajo y la Seguridad Social. Miembro de la Red de Investigadores en Tercerización Laboral (FLACSO). Miembro del grupo de investigadores de la Carta Iberoamericana del Trabajador de la Economía Social Solidaria (UNR). Miembro de la Comisión Directiva y secretario de publicaciones de la Asociación Argentina de Derecho del Trabajo y la Seguridad Social de Córdoba (ADTSS-Cba.). Editor general y subdirector de la revista Catorce Bis de la ADTSS-Cba. Investigador de la Universidad Nacional de Córdoba (CIJS Facultad de Derecho). Disertante y Publicista
} 


\section{I.- Introducción}

La diferencia entre la relación laboral y el contrato de servicios forma parte de uno de los temas más debatidos y desarrollados por la doctrina del Derecho del Trabajo a lo largo de gran parte del siglo XX y comienzos del presente siglo, motivo por el cual, en principio, un nuevo tratamiento sobre dicha temática no revestiría demasiada importancia.

Sin embargo, en los últimos años, y sobre todo desde el plano internacional, han sido incorporados a nuestra legislación nuevos criterios, indicios o indicadores de laboralidad que resultan sumamente útiles a los fines de determinar si nos encontramos frente a una relación de trabajo tutelada por la normativa laboral o a un contrato de servicios, y que se sumaron a los indicadores ya existentes, los que a su vez, han sido objeto de nuevas interpretaciones por parte de la doctrina y de la jurisprudencia.

Por otro lado, la doctrina ha realizado importantes propuestas a los fines de modificar los criterios de laboralidad vigentes con el objeto de adecuarlos a las nuevas formas de trabajo que se presentan en un contexto en permanente transformación, signado principalmente por los cambios tecnológicos².

Desde otro costado, la regulación del contrato de servicios en el CCyC ha establecido nuevos criterios y elementos que adquieren significativa relevancia a la hora de determinar si nos encentramos frente a una relación laboral dependiente o a un contrato de servicios, todo lo cual justifica, entendemos, un nuevo tratamiento de la temática a abordar en el presente trabajo.

\section{La regulación del contrato de servicios en el Código Civil y Comercial}

En el anterior Código, la regulación contrato de servicios (anteriormente denominado contrato de "locación de servicios") 3 no se adecuaba a la realidad negocial contemporánea, debido a que resultaba insuficiente para dar una respuesta apropiada a las variadas cuestiones que podrían suscitarse en un contexto de plena expansión tecnológica con un marcado auge de los servicios como en el que nos encontramos en la actualidad. ${ }^{4}$

Por ello, el CCyC, mediante una nueva regulación, ha buscado adaptarse al citado contexto, comenzando por sustraer a los contratos de obra y servicios de las locaciones, debido a que la anterior regulación estaba asentada sobre la base de su antecedente en el derecho romano, en el cual, el trabajo era realizado por esclavos que eran considerados "cosas", y como tales, susceptibles de locación por parte de sus dueños. ${ }^{5}$

En el actual Código, la sustracción de los servicios del ámbito de las locaciones guarda estrecha razonabilidad en la medida en que "el trabajo no puede ser considerado mercancía", motivo por el cual, resultaría inconstitucional su utilización en tal sentido .

\footnotetext{
2 Véase AAVV, Nuevas Tecnologías, presente y futuro del Derecho del Trabajo, Director ARESE, César, Coordinadores: CHÉRCOLES, Ricardo León y FERRARIO, María de los Ángeles, Editorial Rubinzal Culzoni, Año 2019.

3 Regulado en el Capítulo VIII, del Título VI, de la Sección III, del libro II, del Código Civil.

4 HERNANDEZ Carlos A., Código Civil y Comercial de la Nación Comentado, Director: LORENZETTI, Ricardo Luis, Coordinadores: DE LORENZO, Miguel Federico y LORENZETTI, Pablo, Tomo VI (Arts. 1021 a 1279), Editorial Rubinzal - Culzoni, Santa Fe, Argentina, Año 2015, (edición encuadernada), Pág. 768.

5 GREGORINI CLUSELLAS, Eduardo y GREGORINI Leonardo R, El contrato de servicios y el contrato de trabajo, en Código Civil y Comercial de la Nación y normas complementarias - Análisis doctrinal y jurisprudencial, Tomo 3 D, Artículos 1227 - 1452 Derechos Personales, Director: BUERES, Alberto J., Coordinadores: COMPAGNUCCI DE CASO, Rubén H y GEBHARDT, Marcelo, Editorial Hammurabi - José Luis Depalma, 1ra edición, Buenos Aires, Argentina, año 2018, ISBN 978-950-741-912-6. Pág. 202.

6 PEREZ CRESPO, Guillermo E., El nuevo Código Civil y Comercial y su incidencia en la corrosión del Derecho del Trabajo. El caso particular de
} 
Por otro lado, a través de una renovada metodología y conforme veremos más adelante, el CCyC ha establecido un nuevo criterio para diferenciar la relación laboral dependiente del contrato de servicios, así como también ha propuesto un dialogo entre la regulación del este último con las diferentes normas especiales ${ }^{7}$, dentro de las cuales se encuentra la legislación del trabajo ${ }^{8}$.

Tenemos entonces que, con una franca mejora en la técnica legislativa ${ }^{9}$, el CCyC dedica tres secciones para regular los contratos de obras y servicios: la primera de ellas, con disposiciones comunes a ambas figuras, la segunda, con normas relativas al contrato de obra, y la tercera, con disposiciones referidas exclusivamente al contrato de servicios.

En el marco normativo expuesto, el art. 1251 del CCyC establece que "hay contrato de obra o de servicios cuando una persona, según el caso el contratista o el prestador de servicios, actuando independientemente, se obliga a favor de otra, llamada comitente, a realizar una obra material o intelectual o a proveer un servicio mediante una retribución".

\section{Los puntos de contacto entre la relación de trabajo y el contrato de servicios}

Uno de los problemas para determinar cuándo nos encontramos frente a una relación de trabajo o frente a un contrato de servicios radica en que ambas figuras comparten algunos de sus rasgos o elementos esenciales.

Para comenzar, podemos señalar que tanto uno como otro contrato implican una obligación de hacer por parte de una persona, que involucra la realización de cierta actividad, la cual, en el contrato de servicios se manifiesta en "un hacer con un valor específico"10, mientras que en la relación laboral es "productiva y creadora del hombre en sí" (art. 4to de la LCT). Sin embargo, en ambos casos nos encontramos frente a una actuación, en el sentido de acción u omisión, lo que constituye el primer obstáculo para determinar frente a qué figura nos encontramos.

Además, tanto la tareas que cumple el trabajador como el servicio que realiza el prestador son llevados a cabo con independencia del resultado que con ellos se logre, o dicho con mayor precisión, con independencia de la eficacia del resultado que con ellos se obtenga, contrario a lo que ocurre, por ejemplo, con el contrato de obra ${ }^{11}$, en el cual siempre se promete un resultado reproducible o susceptible de entrega (art. 1252 CCyC). Es por ello que, por ejemplo, conforme lo establece el art. 1278 de nuestro CCyC el contrato de servicios se encuentra estrechamente vinculado con las obligaciones de hacer (reguladas en el art. 773 del citado Código), similar a lo que acontece con la obligación del trabajador, que también configura una obligación de hacer (véase arts. 21, 22, 37 y s.s. de la LCT), sin que en ninguno de los dos casos se exija un resultado eficaz.

los contratos de suministro, obra y servicios, en Derecho del Trabajo, un estudio sobre las implicancias del nuevo Código Civil y Comercial desde una perspectiva crítica, Coordinador: DUARTE, David, Editorial B de F Ltda., 2016, ISBN: 978-9974-745-03-2, Pág. 238 y 239

7 HERNANDEZ Carlos A., Ob. Cit. Pág. 768.

$8 \mathrm{El}$ art. 1252 del CCyC es un ejemplo de ello.

9 LEIVA FERNANDEZ, Luis F. P., Código Civil y Comercial Comentado, Tratado Exegético, Director General: ALTERINI, Jorge Horacio, Directores del Tomo: ALCEGA, María Valentina, GOMEZ LEO, Osvaldo R. y LEIVA FERNANDEZ, Luis F.P, Coordinador: ALTERINI, Ignacio E, Tomo VI (Arts. 1123 a 1377), Editorial Thomson Reuters - La Ley, Buenos Aires, Argentina, Año 2015, ISBN 978-987-03-2925-1. Pág. 561

10 FERNANDEZ BARREDO, Ramiro, Código Civil y Comercial de la Nación, Comentado y Concordado. Tomo II (artículos 957 a 1707), Director VITOLO, Daniel Roque, Prologo de KEMELMAJER DE CARLUCCI, Aida, Editorial Erreius, Buenos Aires, 2015, Pág. 1258. Dicha acción no se desvirtúa porque incluya la fabricación de bienes, puesto que éstos son accesorios a la acción.

11 LEIVA FERNANDEZ, Luis F. P., Ob. Cit. Pág. 564 y 565. Expone el autor que, lo que diferencia al contrato de obra del contrato de servicios es que en el primero de ellos se requiere la obtención de un resultado (obligación de resultado), mientras que en el segundo alcanza con la provisión de un servicio, independientemente del resultado (obligación de hacer). Aunque no resulta indispensable que en el contrato de obra el objeto consista siempre en una obra material, pues puede ser intelectual (científico, literario, artístico, educacional, etc.). La diferencia está en realidad en el compromiso de un resultado. 
Por otro lado, aunque el contrato de servicios puede ser gratuito (art. 1252 CCyC), la regla, al igual que sucede en la relación laboral, es que las tareas o servicios sean llevadas a cabo a cambio de una remuneración o retribución ${ }^{12}$ (arts. 21, 103 y s.s. de la LCT y 1251, 1257 inc. a. del CCyC). Y si bien consideramos que en la relación de trabajo prima el carácter antrópico por sobre el sinalagmático ${ }^{13}$, ello no quita que en ambas figuras el pago de dicha remuneración o retribución constituya uno de sus elementos esenciales, junto con la tarea o el servicio que se lleva a cabo, constituyendo dicho pago, además, la principal obligación tanto del comitente ${ }^{14}(1251,1257$ inc. a. del CCyC) como del empleador (art. 21, 103 y s.s. LCT).

Otros de los puntos en común entre el contrato de servicios y la relación de trabajo está dado por la indeterminación del plazo que rige en ambos casos como regla (art. 1279 CCyC y 90 LCT), regla de la que deriva el deber de preavisar que se establece previo a la extinción de ambos contratos (art. 1279 CCyC y 231 y s.S. LCT).

Asimismo, el contrato de servicios es bilateral, no formal, conmutativo, onerosos y de tracto sucesivo ${ }^{15}$, caracteres todos ellos que comparte con el contrato de trabajo.

Otra similitud entre ambas figuras contractuales está dada por la asunción del riesgo técnico y económico, que en el contrato de servicios recae sobre el comitente ${ }^{16}$, al igual que sucede en la relación de trabajo, en la cual, como sabemos, recae sobre el empleador.

Ya en el plano procesal, al formar parte el contrato de servicios de los contratos no formales, puede ser acreditado a través de cualquier medio de prueba, entre ellos, con la realización misma del trabajo, con testigos y aún a través de presunciones ${ }^{17}$, lo cual, incluso dentro del proceso torna más dificultosa la tarea de determinar si nos encontramos frente a una u otra figura.

Como vemos, los elementos expuestos hasta aquí, por el hecho de ser compartidos por ambos contratos, en principio no podrían ser utilizados como criterios determinantes a los fines de establecer si nos encontramos frente a una relación laboral o a un contrato de servicios, aunque tal afirmación no se encuentra exenta de bemoles, tal como veremos más adelante.

\section{Posibles avances de la regulación del contrato del servicios sobre el Derecho del Trabajo, desde una posición crítica}

Desde una posición crítica, podría considerarse que el art. 1252 del CCyC constituye un avance sobre el Derecho del Trabajo, en la medida en que, a los fines de diferenciar el contrato de obra del contrato de servicios, establece que en el primero de ellos "se

\footnotetext{
12 LEIVA FERNANDEZ, Luis F. P., Ibídem. Pág. 563. Aunque la retribución del prestador de servicios puede no estar integrada en dinero, a diferencia de lo que ocurre con la remuneración que percibe el trabajador (art. 107 LCT). En tal sentido señala el autor que la retribución "puede consistir en la trasferencia de cualquier otro bien, sea en uso o propiedad, en el cumplimiento de un hecho o, incluso, en un no hacer, siempre que implique un beneficio económico para el prestador de servicios o ejecutor de la obra".

13 Véase por ejemplo CHERCOLES Ricardo L, La protección de las remuneraciones del trabajador en accidentes y enfermedades inculpables, en Sección Doctrina On Line, cita RC D 931/2014. Editorial Rubinzal - Culzoni, agosto de 2014.

14 GREGORINI CLUSELLAS, Eduardo y GREGORINI Leonardo R, Ob. Cit. Pág. 225.

15 GREGORINI CLUSELLAS, Eduardo y GREGORINI Leonardo R, Ob. Cit. Pág. 203 y 204.

16 GREGORINI CLUSELLAS, Eduardo y GREGORINI Leonardo R, Ob. Cit. Pág. 214

17 GREGORINI CLUSELLAS, Eduardo y GREGORINI Leonardo R, Ob. Cit. Pág. 205.
} 
promete un resultado eficaz, reproducible o susceptible de entrega", mientras que en el segundo, la obligación consiste en "realizar cierta actividad independiente de su eficacia", frente a lo cual, se podría pensar que todo contrato que conlleve una actividad y no requiera un resultado eficaz (lo que también sucede por ejemplo con las relaciones de trabajo) debería recaer indefectiblemente en un contrato de servicios. ${ }^{18}$

También, desde una posición crítica, podría considerarse que el art. 1279 del CCyC constituye un avance sobre el Derecho del Trabajo, en la medida en que dicha norma establece la posibilidad de que el contrato de servicios sea continuado, y con ello, el citado Código echaría por tierra lo que parte de la jurisprudencia y algunos doctrinarios del Derecho Civil y Comercial sostenían en referencia a que, cuando el contrato de servicios se extendía en el tiempo, sin plazo de finalización, en realidad se estaría encubriendo un contrato laboral. En la actualidad, con el establecimiento del citado artículo, la citada posición doctrinaria y jurisprudencial, que era favorable al trabajador, ha sido descartada por los doctrinarios del Derecho Civil y Comercial ${ }^{19}$.

\section{La regulación del contrato de servicios en el Código Civil y Comercial es progresiva} Más allá de la posición crítica expuesta en el punto anterior, lo cierto es que la regulación del contrato de servicios en el CCyC no pretende abarcar las relaciones laborales dependientes, por el contrario, dicha regulación es clara en establecer un límite entre el citado contrato y la relación de trabajo.

En tal sentido, el art. 1251 del $\mathrm{CCyC}^{20}$ expresamente dispone que el prestador de servicios "actúa en forma independiente", mientras que el art. 1252 del citado Código establece que cuando los servicios son prestados en dependencia serán regidos "por las normas del derecho laboral"21.

Cabe aclarar, por la importancia que ello reviste, que dichas disposiciones no se encontraban establecidas en el anterior Código, y tal como veremos a continuación, su incorporación en el actual posee una significativa relevancia para el Derecho del Trabajo, a nuestro criterio, en favor del sujeto de preferente tutela constitucional.

Es que con anterioridad a la sanción del CCyC, frente a la ausencia de las dos normas citadas más arriba (o de otras en similar sentido), gran parte de la doctrina del Derecho Civil y Comercial sostenía que entre el contrato de servicios y la relación laboral dependiente existía una relación de género a especie, en donde el primero de ellos era el género y la segunda la especie.

En virtud de ello, y aplicando la vieja normativa civil, algunos autores ${ }^{22}$ consideraban que una determinada relación contractual podía encuadrar tanto dentro de los parámetros

\footnotetext{
18 PEREZ CRESPO, Guillermo E., Ob. Cit., Pág. 239 y 240. Ello, entre otras cuestiones que el autor expone en su trabajo, lleva a sostener que existió una voluntad del legislador en avanzar sobre el Derecho del Trabajo, más allá de la aclaración que establece el segundo párrafo del art. 1252 culo cuando reza, como nota de sospechosa ingenuidad (dice el autor), que "los servicios prestados en relación de dependencia se rigen por las normas del derecho laboral". 19 Véase al respecto FERNANDEZ BARREDO, Ramiro. Ob. Cit., Pág. 1281".

20 Art. 1251CCyC:" Hay contrato de obra o de servicios cuando una persona, según el caso el contratista o el prestador de servicios, actuando independientemente, se obliga a favor de otra, llamada comitente, a realizar una obra material o intelectual o a proveer un servicio mediante una retribución".

21 Art. 1252 CCyC: "Si hay duda sobre la calificación del contrato, se entiende que hay contrato de servicios cuando la obligación de hacer consiste en realizar cierta actividad independiente de su eficacia. Se considera que el contrato es de obra cuando se promete un resultado eficaz, reproducible o susceptible de entrega. Los servicios prestados en relación de dependencia se rigen por las normas del derecho laboral. Las disposiciones de este Capítulo se integran con las reglas específicas que resulten aplicables a servicios u obras especialmente regulados".

22 véase LEIVA FERNANDEZ, Luis F. P., Ob. Cit. Pág. 566 y 567
} 
del contrato de servicios como en el marco de una la relación de trabajo, por más que el prestador de los servicios o la persona que llevara a cabo sus tareas o actuara bajo la dependencia de otra. Más aún, algunos doctrinarios encontraban un criterio diferenciador entre el contrato de obra y el contrato de servicios en el hecho de que en el primero de ellos la prestación era independiente, mientras que en el segundo existía subordinación o dependencia. ${ }^{23}$

En la actualidad, estas posiciones doctrinarias que consideraban ciertas relaciones de trabajo dependientes como locaciones de servicios, quedarían descartadas con el nuevo CCyC, al establecer en forma expresa que el prestador de servicios actúa en forma independiente (art. 1251) y que si se actúa bajo dependencia habrá relación de trabajo (art. 1252), desapareciendo también, a raíz de dichas normas, la relación de genero a especie que para algunos autores de la doctrina civil y comercial se daba entre ambas figuras contractuales.

Lo expuesto constituye a nuestro modo de ver, y en materia contractual, un significativo avance del Derecho Civil y Comercial, pero no sobre el Derecho del Trabajo, tal como se ha planteado en un sinnúmero de oportunidades, sino en un sentido protectorio de la persona que trabaja.

Tal vez ello fue lo que con posterioridad a la sanción del nuevo Código llevó a la propia doctrina del Derecho Civil y Comercial a sostener que para determinar si nos encontramos frente a una relación laboral dependiente o a un contrato de servicios, habrá que recurrir primero a los criterios de la legislación del trabajo ${ }^{24}$, utilizando a tales fines, agregamos nosotros, los indicadores y demás herramientas que su normativa nos proporciona, y recién luego de ello, y consideramos que sólo en los casos en que se recurra a la presunción establecida en el art 23 de la LCT, habrá que analizar la cuestión desde los elementos del contrato de servicios regulados en el CCyC.

Es que, tal como lo establece el propio $\mathrm{CCyC}$, no existe una relación de género a especie entre el contrato de servicios y el contrato de trabajo. Por el contrario, este último es autónomo y se encuentra dotado de principios, técnicas y reglas de aplicación derivadas directamente de la protección legal del trabajo (art. 14 bis C.N.), y por otro lado, el CCyC a través de su art. 963 otorga prelación a la LCT (por constituir una "ley especial"), que además resulta indisponible (arts. 7 a 14 LCT). Es por ello que "en caso de colisión o superposición de figuras contractuales de naturaleza laboral y civil y comercial, el operador e intérprete está obligado a posicionarse sobre el derecho sustantivo desde un derecho de protección del hombre en relación de dependencia, cualquiera sea la forma". ${ }^{25}$

En virtud de lo expuesto, será también la justicia del trabajo la que deba intervenir a los fines de determinar si nos encontramos frente a un contrato de servicios o a una relación de trabajo, y más allá de que generalmente es el trabajador quien interpone la acción y "elige" dicho fuero para tramitar su petición, lo expuesto encuentra fundamento tanto en las normas de derecho interno que regulan la competencia como de diferentes Instrumentos Internacionales, tal como por ejemplo se encuentra establecido en la Recomendación 198 de OIT que en su art. 14 establece: “La solución de controversias sobre

\footnotetext{
23 GREGORINI CLUSELLAS, Eduardo y GREGORINI Leonardo R, Ob. Cit. Pág. 214. El autor cita dentro de los doctrinarios que participaban de dicha posición a Llambias. Véase también LEIVA FERNANDEZ, Luis F. P., Ob. Cit. Pág. 566 y 567.

24 HERNANDEZ Carlos A., Ob. Cit. Pág. 765: sostiene textualmente el autor que "Ll primera distinción es determinar si se trata de un vínculo autónomo o dependiente, para lo cual se aplican los criterios de la ley laboral".

25 ARESE, Cesar, Código Civil y Comercial y Derecho del Trabajo, con algunos capítulos de autoría de MACHADO, José Daniel, Editorial Rubinzal Culzoni, Santa Fe, Argentina, año 2017. Pág. 315 y 316.
} 
la existencia y las condiciones de una relación de trabajo debería ser competencia de los tribunales del trabajo o de otros tribunales o de instancias de arbitraje a los cuales los trabajadores y los empleadores tengan acceso efectivo, de conformidad con la ley y la práctica nacionales".

Por lo expuesto, consideramos que la regulación del contrato de servicios en el CCyC es progresiva, en la medida en que ha establecido en forma expresa un límite entre dicho contrato y la relación laboral dependiente, límite que por cierto, como vimos, con anterioridad a la sanción del citado Código se encontraba más alejado del sentido protectorio que tiene nuestro Derecho del Trabajo.

Es que, tal como se ha expuesto, "el contrato de trabajo ha sido la superación dialéctica del contrato de locación de servicios, y por ende, mal podría retrogradarse en su tutela y reconocimiento"26, postulado que el CCyC ha respetado, por lo menos en lo que a regulación del contrato de servicios se refiere.

\section{Los criterios desde la legislación del trabajo y la obligatoriedad de analizar el caso a la luz de las normas del CCyC sólo en el supuesto de recurrir a la presunción del art. 23 de la LCT.}

Como vimos, y según sostiene la propia doctrina del Derecho Civil y Comercial a partir de la sanción de nuestro actual Código, para de determinar si nos encontramos frente a una relación laboral o a un contrato de servicios habrá que partir desde los criterios de la legislación del trabajo.

A tales fines, corresponde recurrir primeramente a los arts. 21 y 22 de la LCT, los cuales, palabras menos y sin querer menospreciar la diferencia existente entre ambas normas, establecen que cuando una persona preste servicios en favor de otra, bajo su dependencia y mediante el pago de una remuneración estaremos frente a una relación de trabajo, tal como coincidentemente vimos que lo dispone el art. 1252 del CCyC.

Pero además, significativa injerencia tendrá en el análisis de la cuestión que nos ocupa el art. 14 de la $\mathrm{LCT}^{27}$, que incorpora el principio de la primacía de la realidad a la legislación laboral, conforme el cual, mientras en una relación contractual se encuentren presentes los presupuestos establecidos en los arts. 21 y 22 de la LCT el contrato será laboral "cualquiera sea su forma o denominación", restando con ello importancia al carácter formal de la relación y ciñendo el análisis a la constatación de los hechos que la conforman.

El problema radica en que la LCT no específica qué debemos entender por "dependencia", como tampoco lo hacen los arts. 1251 o 1252 del CCyC. Sin embargo, la doctrina y jurisprudencia laboral han recurrido, entre otros elementos ${ }^{28}$, a la fragmentación de

\footnotetext{
26 FORMARO, Juan J, El contrato de servicios y el contrato de trabajo, en Código Civil y Comercial de la Nación y normas complementarias - Análisis doctrinal y jurisprudencial, Tomo 3 D, Artículos 1227 - 1452 Derechos Personales, Director: BUERES, Alberto J., Coordinadores: COMPAGNICCI DE CASO, Rubén H y GEBHARDT, Marcelo, Editorial Hammurabi - José Luis Depalma, 1ra edición, Buenos Aires, Argentina, año 2018, ISBN 978-950-741912-6. Pág. 206.

27 Art. 14 LCT: "Será nulo todo contrato por el cual las partes hayan procedido con simulación o fraude a la ley laboral, sea aparentando normas contractuales no laborales, interposición de personas o de cualquier otro medio. En tal caso, la relación quedará regida por esta ley”.

28 Además, a los fines de constatar la existencia de relación de trabajo, la doctrina y jurisprudencia han tomado en cuenta algunos elementos que pueden formar parte o no de las mentadas notas de la dependencia, entre los que podemos mencionar: la prestación de tareas a en forma exclusiva favor una sola persona o conjunto de ellas; la jornada predeterminada de trabajo; el carácter personal de la prestación; la continuidad de las labores; el deber de acatar órdenes; la obligación de cumplir instrucciones; la carencia de titularidad de las herramientas de trabajo; la habitualidad en la percepción de las remuneraciones; la invariabilidad del monto de las mismas; la relativa capacidad económica del dependiente; entre muchas otras, aclarando que la ausencia de alguna o algunas de ellas no podrían llevarnos a descartar la existencia de relación de trabajo.
} 
dicho concepto en sus aspectos técnicos, económicos y jurídicos como forma de verificar si nos encontramos frente a una relación de trabajo o no, aunque cabe aclarar que en ciertas ocasiones alguna o algunas de las referidas notas o aspectos de la dependencia pueden no encontrarse presentes, o pueden presentarse con escasa intensidad, lo que no quiere decir que por ello debamos descartar la existencia de una relación de trabajo.

Entonces, es del juego de los arts. 21 y 22 de la LCT, y desde el prisma del art. 14 de dicha normativa, que deberíamos extraer una conclusión respecto de si nos encontramos frente a una relación laboral o a un contrato de servicios, sin necesidad de recurrir a tales fines a la normativa que regula este último contrato en el CCYC.

Sin embargo podría ocurrir que, aunque se hubiera constatado la prestación de servicios, no se hubiera podido determinar la existencia de una relación de trabajo en los términos de los arts. 21, 22 y 14 de la LCT, supuesto en el cual, resultaría posible recurrir a la presunción iuris tantum que establece el art. 23 de la LCT ${ }^{29}$, en virtud de la cual, de la citada prestación de servicios debe derivarse la existencia de un contrato de trabajo ${ }^{30}$, "aun cuando se utilicen figuras no laborales para caracterizarlo", esto último en consonancia, como vimos, con lo establecido en el art. 14 de la LCT.

Ahora bien, por nuestra parte consideramos que en caso de recurrir a la presunción del art. 23 de la LCT, necesariamente habrá que verificar la existencia de prueba en contrario apta para desactivar la misma ${ }^{31}$, y dicha prueba, entendemos, no puede ser analizada desde otro punto de vista que no sea el la normativa civil y comercial que regula el contrato de servicios, siempre y cuando, claro está, la existencia de dicho contrato hubiera sido la posición fijada por el empleador en el proceso respectivo.

En conclusión: el análisis de la existencia de relación laboral deberá ser hecho exclusivamente desde la legislación del trabajo (arts. 21, 22 y 14 LCT) sin necesidad de recurrir a las normas del Derecho Civil y Comercial, pero en el caso en que se recurra a la presunción establecida en el art. 23 de la LCT, resultará obligatorio el análisis de la prueba en contrario desde las normas que regulan el contrato de servicios en el CCyC.

\section{Criterios de la regulación del contrato de servicios útiles a los fines de desvir- tuar o revalidar la presunción del artículo 23 de la LCT}

Uno de los elementos a tener en cuenta a los fines de determinar si nos encontramos frente a un contrato de servicios o a un contrato de trabajo, y en su caso ratificar o desvirtuar la presunción del art. 23 de la LCT, está dado por la paridad de las partes, en un

\footnotetext{
29 Art. 23 LCT: "El hecho de la prestación de servicios hace presumir la existencia de un contrato de trabajo, salvo que por las circunstancias, las relaciones o causas que lo motiven se demostrase lo contrario. Esa presunción operará igualmente aun cuando se utilicen figuras no laborales, para caracterizar al contrato, y en tanto que por las circunstancias no sea dado calificar de empresario a quien presta el servicio."

30 Cabe hacer un parénesis y señalar que, como es sabido, el art. 23 de la LCT fue interpretado de dos maneras. Para algunos, la sola acreditación de la prestación de los servicios tornaría operativa la presunción que la norma establece, y debido a que tal presunción es iuris tantum, sería el beneficiario de los servicios quien debería demostrar que no existió relación de trabajo entre las partes, mientras que para otros, aunque con algunos bemoles, el trabajador debería acreditar también que dicha prestación fue brindada en el marco de una relación de dependencia, lo que a nuestro modo de ver carecería de sentido y desvirtuaría la propia presunción al tener que probar el prestador de los servicios la existencia de la relación laboral dependiente. Al respecto véase FORMARO, Juan J, Ob. Cit. Pág. 208, en cita a Rosemberg, La carga de la prueba, 2da Ed, 2002, Pág. 255. Señala el autor que se trata de una presunción legal, motivo por el cual, "no es el juez quien de los hechos iniciales extrae una conclusión respecto del hecho presunto, sino que lo ha hecho la ley, no el juez sino la ley presume el hecho. No se trata de la comprobación de hechos sino de la aplicación de derecho, cuando el juez en virtud de la presunción legal toma en consideración el hecho presunto. El juez basa en él su sentencia, no porque se trata de un hecho probado, sino, precisamente, lo hace sin prueba; la presunción hace superfluas la prueba y la verificación del hecho presunto".

31 Posición que ha sido sostenida por nuestra CSJN en el fallo "Rica" que comentamos más abajo.
} 
caso, o la hiposuficiencia de una de ellas respecto de la otra, en el otro, al momento de negociar los términos del contrato.

Es que, aunque no en todos ${ }^{32}$, en la mayoría de los contratos de servicios tanto las cláusulas del contrato como la retribución que percibe el prestador son pactadas por ambas partes (arts. 958 y $1255 \mathrm{CCyC})^{33}$, a diferencia con lo que ocurre en las relaciones de trabajo, en las cuales, como sabemos, existe una hiposuficiencia negocial del trabajador respecto del empleador en tal sentido. ${ }^{34}$

Otro elemento que diferencia ambas figuras está dado por la posibilidad que tiene el prestador de servicios de elegir los medios de ejecución del contrato, facultad de la que el trabajador carece. En este sentido, el art. 1253 del CCyC establece como regla que "el prestador de los servicios elige libremente los medios de ejecución del contrato". A contrario sensu, podríamos derivar de ello que si fue la otra parte quien eligió dichos medios, estaríamos más cerca de una relación de trabajo dependiente que de un contrato de servicios.

La parte sobre la cual recae la dirección y la responsabilidad en la ejecución del contrato constituye otro de los elementos que pueden resultar dirimentes a los fines expuestos. Al respecto, el art. 1254 del CCyC establece que el "prestador de servicios... conserva la dirección y la responsabilidad de la ejecución", motivo por el cual, también a contrario sensu, si en la ejecución del contrato la dirección y responsabilidad quedara en manos del principal, tal como generalmente ocurre en las relaciones de trabajo, podría ser que nos encontremos frente a una de ellas y no frente a un contrato de servicios.

Otro elemento está dado por el hecho de que, como regla, en el contrato de servicios, quien provee los materiales necesarios para la prestación es quien presta dicho servicio (art. 1256 inc. b.), mientras que en la relación de trabajo generalmente es el empleador quien proporciona las herramientas que el trabajador utiliza.

Otra nota distintiva tiene que ver con los riesgos de la actividad del prestador, que en el contrato de servicios generalmente son asumidos por este último ${ }^{35}$, mientras que en la relación de trabajo dependiente son asumidos por el empleador.

Un aspecto muy importante está dado por el conocimiento específico que sobre su actividad debe tener quien la desarrolla en el marco de un contrato de servicios. En este sentido, el art. 1256 inc. a) del CCyC establece la obligación del prestador de ejecutar el contrato conforme los conocimientos razonablemente requeridos al tiempo de su realización por el arte, la ciencia y la técnica correspondientes a la actividad que desarrolla. Cabe aclarar que tal estipulación, no se encontraba establecida en el anterior Código Civili36, sino que fue incorporada por el actual, y guarda estrecha correspondencia tanto con la revalorización que el CCyC ha hecho de la capacidad del prestador del servicio como con el carácter de independiente (art. 1251 CCyC) que debe revestir su actuación.

\footnotetext{
32 Habrá que ver si se trata de contratos paritarios (art. 957 CCyC), de adhesión (art. 984 CCyC) o de consumo (art. 1093).

$33 \mathrm{Tal}$ es así que, por ejemplo, el art. 1255 del CCyC establece que las "leyes arancelarias no pueden cercenar la facultad de las partes para determinar el precio de las obras o los servicios.

34 De ello se deriva que, si en el caso concreto las partes negociaron las cláusulas del contrato, tendríamos un indicio de que podría acercarnos a un contrato de servicios. Si por el contrario el prestador del servicio no negoció las cláusulas sino que las mismas fueron dispuestas por la otra parte, nos encontraríamos más cerca de una relación de trabajo dependiente.

35 LEIVA FERNANDEZ, Luis F. P., Ob. Cit. Pág. 566 y 567.

36 Que en su art. 1632 establecía que se debía hacer según la costumbre del lugar..."
} 
Lo expuesto también surge del deber de información que pesa sobre el prestador de servicios frente al comitente (art. 1256 CCyC), del que se deriva que "el prestador o contratista generalmente es un profesional, artesano o artista que posee un conocimiento experto sobre su área de especialización" ${ }^{137}$, motivo por el cual, debe informar a quien lo contrata. Por lo expuesto, y también a contrario sensu, al tratarse de una persona que no hubiere sido contratada por su conocimiento en el arte, la ciencia o la técnica, podríamos presumir que nos encontramos frente a una relación laboral. Cabe agregar que el citado conocimiento especial que sobre su actividad tiene el prestador de servicios constituye un elemento muy utilizado en el derecho comparado a los fines de constatar frente a qué figura nos encontramos, y por otro lado, podemos decir también que "el desempeño de una profesión liberal no descarta su realización bajo dependencia"38.

Especial mención merece además la ausencia de dependencia técnica con que el prestador desarrolla su actividad en el marco del contrato de servicios, lo que también ha sido una incorporación del actual CCyC.

En el anterior Código se encontraba estipulado que el modo de ejecutar la obra debía adecuarse a la costumbre del lugar o a lo decidido por las partes teniendo en consideración el precio estipulado (art. 1632 CCyC), mientras que en el CCyC se optó por brindar a quien ejecuta la obra el poder de decidir el modo en que va a llevarla a cabo. Es así que la propia doctrina del derecho Civil y Comercial ha dicho que "el contrato de obra y servicios se presenta en el CCyC como expresión de la libre prestación de actividad en el tráfico jurídico por contraposición al trabajo bajo relación de dependencia. No es de extrañar, consecuentemente, que el contratista o prestador pueda seleccionar libremente los métodos para cumplir con la obligación asumida. En otros términos, el artículo consagra la denominada discrecionalidad técnica que constituye una de las características del trabajo autónomo... Existe, por regla, la libertad de método"39. En el mismo sentido los autores del Derecho Civil y Comercial han sostenido que la diferencia principal entre un contrato de servicios y una relación de trabajo radica en que "el prestador tiene discrecionalidad técnica, o sea, es él quien elige los medios y la forma que utiliza para la ejecución del contrato, tal como lo dispone el artículo 1253 del CCyC..."10. En otras palabras, el art. 1253 del CCyC "consagra la autonomía técnica del prestador de servicios ${ }^{41}$, por lo que, frente a la carencia de dicha autonomía en el caso concreto, deberíamos inclinarnos por resolver que nos encontramos frente a una relación de trabajo en detrimento de un contrato de servicios.

\section{VIII. ¿Una revalorización del contrato de servicios frente a la relación de trabajo? A raíz de los fallos "Cairone" y "Rica" de la CSJN}

Con fecha 19 de febrero de 2015, en autos "Cairone, Mirta Griselda y otros c/ Sociedad Italiana de Beneficencia en Buenos Aires - Hospital Italiano s/ despido", la CSJN revocó una sentencia de la Sala I de la Cámara Nacional de Apelaciones del Trabajo que había hecho lugar a un reclamo por despido injustificado incoado por los herederos de un médico anestesiólogo que había prestado sus servicios en el Hospital Italiano ${ }^{42}$.

\footnotetext{
37 FERNANDEZ BARREDO, Ramiro. Ob. Cit., Pág. 1262

38 GREGORINI CLUSELLAS, Eduardo y GREGORINI Leonardo R, Ob. Cit. Pág. 203

39 LEIVA FERNANDEZ, Luis F. P., Ob. Cit. Pág. 580 y 581

40 FERNANDEZ BARREDO, Ramiro. Ob. Cit., Pág. 1258

41 GREGORINI CLUSELLAS, Eduardo y GREGORINI Leonardo R, Ob Cit. Pág. 216

42 La sentencia de Cámara había resuelto a favor del trabajador con fundamento en el art. 23 de la LCT, y teniendo en cuenta que el actor cumplió tareas como médico anestesiólogo en forma habitual en el Hospital Italiano, integrando el plantel de la accionada, resultando su tarea parte de un engranaje empresario, destacando, entre otros motivos: la carga horaria, las guardias pasivas y activas que debía cumplir el actor, la dirección y conducción del
} 
En lo que a la temática del presente capítulo concierne, la Corte revocó ${ }^{33}$ el fallo porque la Cámara había llevado a cabo una incorrecta aplicación del art. 23 de la LCT sin analizar el caso a la luz de la normativa relativa a la locación de servicios regulada por el Código Civil.

Sostuvo también el máximo Tribunal de nuestro país que: 1. la sentencia había ignorado las consecuencias jurídicas, económicas y sociales que excedían el caso y que repercutían sobre todo el sistema de contrataciones, 2. el actor no había obrado con buena fe puesto en los 32 años que había prestado servicios nunca había hecho reclamo alguno, resultando su posterior accionar contrario a la doctrina de los actos propios ${ }^{44}$, 3. la Cámara omitió valorar la costumbre como fuente de derecho, lo que era i portante debido a su injerencia en una relación contractual tan particular como la del caso ${ }^{45}$.

En lo estrictamente relacionado a la dependencia, sostuvo la Corte que ésta presenta tres aspectos: uno jurídico, uno económico y otro técnico, agregando que en una relación laboral se trabaja por cuenta ajena, lo que significa que el beneficio de las labores que se realizan es para el empresario, no para el trabajador. Por tal motivo, dijo la Corte, en las relaciones laborales el trabajador es ajeno a los riesgos, y percibe una remuneración de la que depende para su subsistencia con independencia de que el empleador gane o pierda en su actividad ${ }^{46}$.

Por último, nuestro máximo tribunal señaló que la sentencia de Cámara confundió la dependencia con el control que es propio de los contratos de colaboración y que debe estar presente en todo establecimiento que preste servicios a terceros ${ }^{47}$, agregando que si bien un trabajador dependiente siempre está sometido al poder de dirección del empleador, dicha dirección también se encuentra presente en el trabajo autónomo ${ }^{48}$.

Más de 3 años después, con fecha 24 de abril de 2018, en autos "Rica, Carlos Martín c/ Hospital Alemán y otros s/ despido", la CSJN revocó una sentencia de la Sala VII CNAT que había hecho lugar a la indemnización por despido injustificado y al reclamo de las multas derivadas de la Ley de Empleo que había llevado a cabo un médico neurocirujano ${ }^{49}$.

establecimiento hospitalario por parte de la demandada, la integración del actor en la organización empresaria demandada, el control por parte de la accionada sobre la tarea del médico, entre otros fundamentos.

43 La sentencia fue revocada vía doctrina de la arbitrariedad, con votos de los Ministros Elena I. Highton de Nolasco, Juan Carlos Maqueda y Ricardo Luis Lorenzetti adhiriendo al dictamen de la procuradora, con el voto del Dr. Lorenzetti en concurrencia.

44 Expuso la CSJN que la Cámara no pudo desconocer el comportamiento asumido por el actor quien, por decisión propia y voluntaria, pudo evaluar la conveniencia de desarrollar su tarea en el centro asistencial demandado del modo efectuado, durante más de 32 años, sin manifestar conflicto alguno atinente al encuadramiento jurídico de la relación que los unió (considerando $7 \mathrm{mo}$ ). Agregó que la resolución impugnada tampoco considera la buena fe como deber jurídico de todo comportamiento que genera expectativas en otras personas. La prestación que desarrolló el doctor Estala tuvo el mismo carácter durante todo el tiempo que duró la relación, emitió facturas a través de la "AAARBA" y nunca hizo reclamo alguno. Solo manifestó su discrepancia al momento del distracto, conducta que contraría sus propios actos y la regla de la buena fe, al quebrar, sin causa fundada, la razonable expectativa de la institución que lo contrató durante tantos años sobre la base de una relación jurídica de servicios autónomos (considerando 11vo).

45 Sostuvo la Corte que la costumbre del sector, como fuente de derecho, también fue ignorada en el fallo recurrido. En ese orden de consideraciones, el a quo también ha omitido toda valoración respecto de la información brindada por la "Fundación Favaloro" sobre la situación laboral de los médicos anestesiólogos, en donde la "AAARBA" contestó afirmando el carácter de "locación de servicios" de las tareas desempeñadas por sus socios (fs. 488/489) (considerando 11vo)

46 Sostuvo la Corte en el fallo: "Por ello, aunque, hay una gran variedad de remuneraciones que es posible pactar entre empleado y empleador (fija, variable, etc.), lo importante es la función económica de la prestación dineraria. En el contrato laboral la obligación dineraria tiene una función retributiva, ala que la ley, además, le atribuye, como mínimo, la finalidad de asegurar alimentación adecuada, vivienda digna, educación, vestuario, asistencia sanitaria, transporte y esparcimiento, vacaciones y previsión (art. 116, ley 20.744). Esta causa económico-social es otro elemento que concurre a la tipificación del vínculo, que no se da en el caso".

47 Sostuvo la Corte en el fallo: "En los vínculos de colaboración autónomos hay una intromisión o injerencia del titular del interés sobre quien realiza la colaboración y está destinada a precisar el objeto del encargo. Dicha injerencia es distinta de la dependencia laboral, ya que esta última no se limita al objeto del encargo pues alcanza al elemento personal, al trabajador, que está jurídicamente subordinado."

48 Esta dirección se plasma en el modo de prestación con referencia a los horarios, lugar, medios técnicos a utilizar, fijación del ritmo de trabajo, entre otros aspectos.

49 En su sentencia la Cámara tuvo por acreditado que el actor prestó servicios en el ámbito del Hospital Alemán. Resaltó que el ejercicio de una profesión 
En lo que a la cuestión que nos atañe refiere, la Corte revocó el fallo ${ }^{50}$ criticando la posición de la Cámara que había sostenido que el contrato de locación de servicios se encontraba virtualmente abrogado y que su utilización resultaba inconstitucional ${ }^{51}$. Al respecto, la Corte expuso que, por el contrario, dicho contrato se encontraba vigente (en el art. 1623 del Código Civil, hoy 1251 del (CyC), y que además, era un contrato civil típico y habitual en el ámbito de los servicios profesionales, tal es así, dijo la Corte, que el art. 23 de la LCT al establecer una presunción iuris tantum admite que la prestación sea cumplida en una forma ajena a la relación laboral dependiente.

Sostuvo además el máximo Tribunal de nuestro país que en el caso concreto: 1. los propios médicos eran quienes decidían a quien se contrataba y quienes tenían injerencia en la forma en que se desarrollaba el servicio que se prestaba en el establecimiento ${ }^{52}$ y 2 . el actor recibía una contraprestación por sus servicios sólo si los mismos eran efectivamente prestados.

Asimismo la Corte señaló que existieron otras circunstancias adicionales que si bien no resultaban per se determinantes del tipo de relación que vinculaba al actor con las demandadas debieron ser analizadas por el Tribunal. Entre ellas podemos destacar: 1. que el actor era monotributista y emitía facturas no correlativas cuyos importes diferían todos los meses ${ }^{53}$; 2. que la AFIP había realizado una inspección en el Hospital Alemán y concluyó que no existía relación de dependencia con el actor; 3. que el actor nunca reclamó la existencia de una relación laboral durante toda su relación de trabajo; 4. que el actor no probó ni invocó que hubiera gozado de vacaciones pagas y 5 . que cada médico podía fijar sus propios horarios. Además, agregó el máximo Tribunal de nuestro país que no alcanzaba para acreditar una relación dependiente el hecho de que el actor hubiera concurrido todos los días a trabajar, que trabajara en el establecimiento propiedad del Hospital Alemán y que sus honorarios hubieran sido la única fuente de sus ingresos.

En lo que estrictamente a la dependencia se refiere, y similar a lo que sostuvo en el fallo "Cairone", la CSJN expuso que el hecho de que un prestador de servicios deba respetar una serie de directivas emanadas de quien lo contrató no resulta por sí solo concluyente para acreditar un vínculo de subordinación, debido a que ciertas exigencias responden al orden propio de toda organización empresarial y pueden estar presentes tanto en el contrato de trabajo como en una relación de carácter comercial. En tal sentido, sostuvo la Corte que si se entiende que la sola verificación y control supone un trabajo dirigido, podría llegarse a la inexacta conclusión de que la mayoría de las prestaciones médicas son dependientes, puesto que normalmente se ejerce un control sobre dichas prestaciones.

\footnotetext{
liberal no era obstáculo para que se perfeccionara un contrato de trabajo cuando las tareas eran habituales y continuas. Asimismo, estimó: que el actor se había insertado en el establecimiento y la organización de trabajo del citado hospital; que las demandadas abonaban sus honorarios y que el actor había utilizado los elementos que la accionada le proveía para poder desarrollar sus tareas. A partir de ello, y teniendo en cuenta que prestación de servicios había sido reconocida por parte de las accionadas, con fundamento en el art. 23 de la LCT, concluyó que existió un contrato de trabajo.

50 La sentencia de la CNAT fue revocada por la Corte vía doctrina de la arbitrariedad, con votos de los Ministros Elena I. Highton de Nolasco, Juan Carlos Maqueda, Horacio Rosatti, Carlos Fernando Rosenckrantz y Ricardo Luis Lorenzetti adhiriendo al dictamen de la procuradora, con el voto del Dr. Lorenzetti en concurrencia.

51 Con respecto a la locación de servicios que habían invocado los demandados, la Cámara sostuvo que "en los últimos cincuenta años ningún civilista destacado ha aceptado la existencia de este contrato y todos han dado cuenta de su abrogación". Afirmó además que "el contrato de locación de servicios no existe más en ningún ámbito del derecho; si alguien intentara utilizarlo estaría desarrollando una conducta inconstitucional ya que el trabajo no es una mercancía y que goza de la protección de las leyes entrando ya ahora en el art. 14 bis.". En tal sentido, juzgó a la suscripción de dichos convenios como actos fraudulentos contrarios al orden público laboral (extraído del fallo de la Corte)

52 De ello se deriva que la institución no estaba facultada para introducir por su sola voluntad cambios en una modalidad esencial del contrato de trabajo 53 Sostuvo la Corte que la ajenidad del riesgo es un elemento distintivo de la prestación de servicios en el marco de una relación de subordinación, debido a que el dependiente tiene una base de ingresos fija y regular asegurada. En cambio, quien ejerce en forma autónoma, tratándose de un profesional médico, su ingreso depende de si los pacientes directamente o bien la obra social o el intermediario financiero realicen el pago.
} 
Sobre los dos pronunciamientos citados podemos señalar que, si bien en ambos casos existían ciertas particularidades ${ }^{54}$ que impiden trasladar los fundamentos de la Corte a otros casos que no las presentan, y que además si bien dichas particularidades podrían haber llevado a cualquier Tribunal a descartar una relación de dependencia en favor de un contrato de servicios, resultan llamativos algunos de los fundamentos utilizados por la Corte a los fines de fijar su postura.

Entre ellos, no podemos dejar de reparar en la utilización por parte del máximo Tribunal de nuestro país de la teoría de los actos propios, en la medida en que dicha teoría tiene escasa aplicación en el Derecho del Trabajo debido a que, por un lado, su utilización otorga cierta legitimidad a casos de fraude laboral, y por el otro, existe una clara imposibilidad del trabajador de reclamar a su empleador mientras se encuentra vigente su relación de laboral por miedo a perder su fuente de empleo, lo que justifica su inacción frente al principal. Ello ha llevado incluso a algún autor a habar de una hiposuficiencia reclamacio$n a{ }^{55}$ del trabajador en el marco de las relaciones de labor.

A su vez, la posición de la Corte en el sentido de ambos fallos olvida la protección del trabajo "en sus diversas formas" (art. 14 bis C.N.) y vulnera el principio de irrenunciabilidad, del cual se deriva la imposibilidad de la aplicación de la teoría de los actos propios, que según la propia Corte ${ }^{56}$ carecerán de todo valor los actos de renuncia expresa o tácita que efectúe el titular del derecho, en cuanto carece de la facultad jurídica de desprenderé de los derechos que las normas imperativas de jerarquía constitucional o supralegal le conceden. ${ }^{57}$

Tampoco podemos dejar de señalar el destacado valor que la CSJN otorgó a las consecuencias económicas que podía acarrear el pronunciamiento. Y si bien no es la primera vez que la Corte refiere dichas consecuencias ${ }^{58}$, la citada posición había sido superada a partir de la propia jurisprudencia de la Corte que llevó a una valoración de la persona humana por sobre las referidas consecuencias ${ }^{59}$, incluso definiendo principios y reglas en tal sentido ${ }^{60}$. 54 V.gr: en "Cairone" El actor, como médico anestesiólogo, tenía una relación con la Asociación de Anestesia, Analgesia y Reanimación de Buenos Aires
(AAARBA) de la cual era socio y actuaba como agente de facturación y cobro de sus honorarios, además de ser agente de retención de diversas obligaciones
impositivas, como así también de la cuota de la empresa de medicina prepaga contratada por el afiliado, de la comisión cobrada por la AAARBA por sus
servicios, del pago del seguro por mala praxis contratado a través de la Mutual de Médicos Anestesiólogos, entre otros conceptos (extraído del considerando
6to del fallo).

55 ELIAS, Jorge, Hiposuficiencia reclamacional, un nuevo desafío para el derecho del trabajo, en Revista Derecho del Trabajo, Thomson Reuters - La Ley, Buenos Aires, Pág. 3196.

56 En fallos "Ambrogio" y "Perez Ortega"

57 DUARTE, David, La Relación de Trabajo, en Jurisprudencia laboral de la Corte Suprema Justicia de la Nación comentada, Director: ACKERMAN, Mario E., Coordinadora: SFORSINI, María Isabel, Tomo I, Editorial: Rubinzal Culzoni, Santa Fe, Año 2019, Pág. 39 y 40.

58 Entre otros, por ejemplo, "Rodríguez c Embotelladora".

59 CSJN: Fallo Vizzoti: "La Corte no desconoce, desde luego, que los efectos que produzca la doctrina del presente fallo podrían ser considerados, desde ciertas posiciones o escuelas, como inadecuados a los lineamientos que serían necesarios para el mejoramiento del llamado mercado de trabajo, cuando no del mercado económico en general. Esta hipotética censura, sin embargo, al margen de la naturaleza sólo conjetural de las consecuencias que predica, resulta manifiestamente desechable. Puesto que, seguramente de manera involuntaria, omite hacerse cargo de que su eventual consistencia exige ignorar o subvertir tanto el ya mentado principio de supremacía de la Constitución Nacional, cuanto el fundamento en el que toda ésta descansa según el texto de 1853-1860, robustecido aún más por los señeros aportes del art. 14 bis y la reforma de 1994 (esp. art. 75 inc. 22). Consentir que la reglamentación del derecho del trabajo reconocido por la Constitución Nacional, aduciendo el logro de supuestos frutos futuros, deba hoy resignar el sentido profundamente humanístico y protectorio del trabajador que aquélla le exige; admitir que sean las "leyes" de dicho mercado el modelo al que deban ajustarse las leyes y su hermenéutica; dar cabida en los estrados judiciales, en suma, a estos pensamientos y otros de análoga procedencia, importaría (aunque se admitiere la conveniencia de dichas "leyes"), pura y simplemente, invertir la legalidad que nos rige como Nación organizada y como pueblo esperanzado en las instituciones, derechos, libertades y garantías que adoptó a través de la Constitución Nacional".

60 Véase ARESE Cesar, Derechos Humanos Laborales. Teoría y práctica de un nuevo derecho del trabajo. Prólogo de BYLOS, Antonio. Editorial RubinzalCulzoni. Santa Fe, Argentina. Año 2014. Pág. 69 a 89. Véase en especial el capítulo II de la obra, denominado "Principiología laboral de la Corte Suprema", en el que autor expone los principios desarrollados por la CSJN en sus diferentes pronunciamientos, sobre todo a partir del año 2004. Entre dichos principios el autor destaca el: protectorio; de estabilidad laboral; justicia social, progresividad; pro homine, favorabilidad; reparación integral, igualdad y no discriminación; distribución desigual de las cargas probatorias en procesos por discriminación; supremacía constitucional en la negociacion colectiva; libertad y democracia sindical, todos ellos sostenidos por la CSJN en los fallos "Milone"; "Aquino"; Vizzoti"; "Madorrán"; "ATE s/ Inconstitucionalidad"; 
Por otra parte, la alusión a las consecuencias económicas en un determinado pronunciamiento, tal como sucedió en "Cairone"61, remite a una idea de "consecuencialismo" de los pronunciamientos jurisprudenciales, la cual, no sólo vulnera el debido proceso por resultar ajena al caso sino que también carece de fundamentación en Derecho. ${ }^{62}$

Llama también la atención la referencia que hizo la Corte en el sentido de que, en las relaciones laborales el beneficio del trabajo va para el empresario y no para el trabajador, quien percibe una remuneración de la que depende para su subsistencia, cuando tal posición ha sido descartada por gran parte de la doctrina en la medida en que, por un lado, en muchas relaciones laborales parte del beneficio del trabajo también queda para el trabajador, y por el otro, es sabido la falta de dependencia económica y no excluye la relación de trabajo.

Por último, entre otras cuestiones ${ }^{63}$, resulta llamativo que la sentencia de la Corte hubiera separado el "control" de una parte por sobre la otra de la "dependencia" existente entre ambas, debido a que dicho control constituye en realidad uno de los elementos o notas de la citada dependencia, tal es así que de dicho modo se encuentra expresamente establecido en diferentes instrumentos internacionales, tal como veremos a más adelante.

\section{La renovación de los indicadores de laboralidad a raíz de las trasformaciones tecnológicas en el ámbito de los servicios}

Desde finales del siglo pasado, pero con mayor intensidad en nuestros días, nuevas realidades y diferentes factores demográficos; migratorios; climáticos; de oferta y demanda de trabajo; sumados a recientes formas de contratación, métodos de producción, distribución y consumo, y al impacto de las transformaciones tecnológicas instauradas sobre instituciones, acuerdos y regímenes de libre comercio, todo ello sobre la base de un creciente neoliberalismo a escala global, entre otras causas, han traído aparejadas una serie de consecuencias que se manifiestan hoy en diferentes aspectos del trabajo humano. ${ }^{64}$

Entre dichas consecuencias se destaca la aparición y el posterior desarrollo de nuevas formas de labor, que fueron denominadas por la OIT como formas atípicas ${ }^{65}$ de trabajo, cuya principal característica, a nuestro modo de ver, está dada por el desvanecimiento o la desaparición de algunos de los elementos que conforman la dependencia de quien lleva a cabo sus tareas o presta sus servicios en el marco de tales formas de labor.

\footnotetext{
"Perez c Disco"; "Llosco”; “ATE II”; “Álvarez"; “Aróstegui”; "Rossi”; “Pellicori”, entre muchos otros.

61 En el fallo la Cámara había condenado a la Sociedad Italiana de Beneficencia en Buenos Aires al pago de más de \$4.500.000, más intereses.

62 DUARTE, David, Ob. Cit, Pág. 35 y 36: En tal sentido sostiene el autor que el fallo "se aparta de las cuestiones debatidas y afecta el principio de congruencia y la garantía de defensa en juicio, porque es un argumento que se introduce luego del resultado de la decisión judicial, que tiene en cuenta los hechos alegados por las partes, sometidos a las reglas del proceso, a los que se agregan los aspectos controvertidos y que se someten a las pruebas en juicio, también a la evaluación y ponderación de cada una de las constancias probatorias. A su vez, los hechos probados son sometidos a su encuadre a la norma legal aplicable que conduce al resultado de la actividad jurisdiccional... Es la degradación del Derecho por parte de la economía que tiene en cuenta otras circunstancias que no deben formar parte de la actividad jurisdiccional".

63 Resulta extraño también el valor que la Corte le dio a la costumbre como fuente de derecho por sobre otros aspectos que consideramos más relevantes. 64 Véase en CHERCOLES, Ricardo León y FERRARIO, María de los Ángeles, El impacto de las transformaciones tecnológicas y el futuro del Derecho del Trabajo en América Latina, con especial referencia a los trabajadores vulnerables, en Nuevas tecnologías, Presente y futuro del Derecho del Trabajo, ARESE, Cesar, Director, CHERCOLES, Ricardo y FERRARIO María de los Ángeles, Coordinadores. Editorial Rubinzal Culzoni, Año 2019, ISBN: 978-987-30-13997. Pág. 137 a 171.

65 La denominación "atípica" ha sido utilizada por la OIT en su programa denominado "Iniciativa del centenario relativa al futuro del trabajo". Conforme los diferentes informes de la citada Organización dichas formas de trabajo comprenden las "ocupaciones transitorias o por encargo", el trabajo "tecnológico calificado", el trabajo "no remunerado", el "empleo ambiguo", el trabajo "ondemand", la "gigeconomy", el "coworking", entre otras formas de labor que también incluyen el trabajo desarrollado en el marco de aplicaciones o plataformas digitales (v.gr: Uber, Cabify, Rappi, Pedidos ya, Golvo, Deliveroo, Foodora, entre otras).
} 
Pero además del desvanecimiento o la desaparición de algunas de las notas de la dependencia, en los últimos tiempos el trabajo ha experimentado una ruptura del límite espacial-temporal que constituía la esencia y estructura básica de la relación de trabajo fordista dependiente sobre la cual se construyó nuestro actual Derecho del Trabajo, y conforme la cual, el trabajo humano se limitaba a la prestación de tareas específicas dentro de un establecimiento dado y a lo largo de una jornada determinada. ${ }^{66}$

Sin embargo, a pesar de los mentados cambios, el modelo de nuestro Derecho del Trabajo concebido sobre la base de la citada relación laboral fordista dependiente continúa sin grandes transformaciones estructurales en nuestros días. Es decir, la existencia de dependencia económica, técnica y jurídica del trabajador hacia el empleador como elemento necesario para que el primero pueda gozar de la protección de las normas propias del Derecho del Trabajo permanece, por lo menos desde la praxis, incólume en la actualidad, lo que podría llevar a que muchas de las formas de trabajo atípicas queden fuera del paraguas protectorio del Derecho Laboral, y terminen enmarcadas en diferentes tipos de contratos de servicios.

Prueba de ello está en que la mayoría de las sentencias que en el derecho comparado ${ }^{67}$ analizaron la existencia de una relación de trabajo en el contexto de las formas atípicas de labor, (por ejemplo en el marco de plataformas digitales), rechazaron, con diversos fundamentos ${ }^{68}$, la pretensión de los trabajadores cuando tales casos fueron analizados desde la óptica de la dependencia técnica, jurídica y económica, y por el contrario, cuando dichas sentencias analizaron la existencia de relación laboral desde otra óptica o utilizando otros métodos, criterios, indicios, indicadores de laboralidad, hicieron lugar a los reclamos de los accionantes. ${ }^{69}$

Entonces, el problema radica en que el desvanecimiento o la desaparición en los elementos que configuran la dependencia laboral (técnica, económica y jurídica) en las formas de trabajo atípicas, y el mantenimiento de un derecho que sólo protege cuando dicha dependencia se encuentra presente con cierta intensidad, podría llevar a la desprotección de quienes desarrollan su actividad o prestan sus servicios en el marco de las citadas formas de labor.

Y el problema podría ser aún mayor, debido a que diferentes estudios llevados a cabo por distintos organismos internacionales muestran que las formas de trabajo atípicas en el marco de los servicios (v.gr: trabajo en plataformas digitales), que hoy no alcanzan el 1,5\% del trabajo total, en menos de 15 años podrían superar el 50\% del total de las formas de trabajo, con lo que podríamos tener más de la mitad de los trabajadores

66 En la actualidad, la ruptura de dichos límites en el trabajo ha traído aparejadas una serie de consecuencias que han llevado al resquebrajamiento del derecho que lo regula, y a que muchos de sus institutos resulten ineficientes e incluso inaplicables para la regulación tanto de las formas de trabajo atípicas como de las formas de labor no subordinadas, pero también a que algunos de los principios rectores de dicho derecho resulten incompatibles con las citadas formas de trabajo.

67 No se citan sentencias dictadas en el marco de nuestro ordenamiento jurídico interno porque no las hay hasta la fecha. Por lo menos no analizando la existencia de relación de trabajo en tales marcos.

68 Los fundamentos fueron: que el trabajo no es personal (se prevé el reemplazo por otra persona); las herramientas del trabajo son del propio prestador de servicios y pueden ser utilizadas por éste en actividades no relacionadas con el trabajo; el prestador de servicios asume los gastos de su actividad (gasolina, peajes, comida, seguro, impuestos etc.); el prestador de servicios asume los riesgos de su actividad (v.gr. rotura de auto o bicicleta); en los contratos se hace referencia al "prestador" y nunca al "trabajador"; en los contratos existe libre voluntad de las partes; hay libertad en la determinación de la jornada de trabajo por parte del prestador de servicios (los días y horas de prestación); el prestador de servicios puede rechazar encargos o rehusar encargos previamente elegidos; no existe dependencia técnica en la relación (el prestador es libre para organizarse como quiera en la prestación del servicio: medios de transporte, rutas etc.); el prestador no tiene exclusividad para con el dador de trabajo; el prestador de servicios es quien recibe el pago directamente del cliente y luego deposita los montos al dador del trabajo.

69 Véase https://ignasibeltran.com/2018/12/09/employment-status-of-platform-workers-national-courts-decisions-overview-australia-brazil-chile-franceitaly-united-kingdom-united-states-spain/ Accedido el 10/06/19 
o prestadores de servicios hiposuficientes sin protección y trabajando en contextos de suma vulnerabilidad

¿No sería entonces hora de cambiar la constatación de la dependencia técnica, jurídica y económica por otros indicadores de laboralidad a los fines de no poner en riesgo la protección de dichos trabajadores?

\section{La relación de trabajo y el contrato de servicios a la luz de la Recomendación 198 de la OIT}

Sin embargo, en nuestro ordenamiento jurídico existen otros indicadores de laboralidad más allá de la citada constatación de la dependencia técnica, económica y jurídica, aunque los mismos no son frecuentemente utilizados por los diferentes operadores jurídicos.

A modo de ejemplo podemos mencionar que, a los fines de adaptarse a los cambios que han experimentado las formas de trabajo, y sobre todo con el objetivo de evitar el fraude a través de la utilización de contratos de servicios no laborales para encubrir verdaderas relaciones de trabajo, el Derecho Laboral ha dado algunos pasos.

Es así que en el año 2006 la OIT dictó la Recomendación 198 “Sobre la relación de trabajo", cuyo artículo 13 establece la necesidad de contar en la legislación de cada país, aunque también ello puede ser llevado a cabo por otros medios, con indicios específicos que permitan determinar la existencia de una relación de trabajo tutelada.

Para la citada Recomendación, forman parte de dichos indicios que el trabajo: 1. se realice según las instrucciones y bajo el control de otra persona; 2 . implique la integración del trabajador en la organización de la empresa; 3. sea efectuado única o principalmente en beneficio de otra persona; 4. deba ser ejecutado personalmente por el trabajador, dentro de un horario determinado, o en el lugar indicado o aceptado por quien solicita el trabajo; 5. tenga cierta duración y continuidad, o requiera la disponibilidad del trabajador; 6 . implique el suministro de herramientas, materiales y maquinarias por parte de la persona que requiere el trabajo.

También conforme la citada Recomendación dichos indicios se encuentran en el hecho de que: 1. se paga una remuneración periódica al trabajador; 2. dicha remuneración constituye la única o la principal fuente de ingresos del trabajador; 3. la citada remuneración incluye pagos en especie tales como alimentación, vivienda, transporte, u otros; 4. se reconocen derechos como el descanso semanal y las vacaciones anuales; 5. la parte que solicita el trabajo paga los viajes que ha de emprender el trabajador para ejecutar su trabajo; y 6. no existen riesgos financieros para el trabajador.

Cabe señalar que algunos de los indicios o indicadores de laboralidad establecidos en la Recomendación N ${ }^{\circ} 198$ de la OIT hacen a las notas típicas de la dependencia técnica, económica o jurídica, sin embargo, otros amplían el espectro de dicha dependencia o incluso constituyen indicadores que no se circunscriben a lo que la doctrina ha entendido por dependencia o subordinación, pero no por ello dejan de ser indicios de la existencia de una relación de trabajo que debe ser tutelada por el derecho de cada país, y en particular del nuestro, conforme el carácter y alcance que la citada Recomendación tiene. 


\section{Algunos pasos se han dado y otros se han propuesto}

Entre los indicadores aptos para analizar la existencia de una relación de trabajo tutelada cuando la misma se hubiere desarrollado fuera del molde de la típica relación fordista dependiente podemos destacar la verificación de la integración del trabajador en la organización de la empresa, indicador éste que se encuentra plasmado, como vimos, en la Recomendación 198 de la OIT, además de encontrarse también establecido en algunos ordenamientos jurídicos internos ${ }^{70}$.

Otro indicador útil a los fines mencionados está constituido por el concepto de ajenidad o del trabajo por cuenta ajena ${ }^{71}$, que comprende diferentes variantes tales como la ajenidad en los riesgos, en los frutos, en los resultados y/o en la titularidad de la explotación, aunque en nuestro Derecho del Trabajo dichas variantes no resulten puras o absolutas y admitan algunos matices ${ }^{72}$.

También, como posible criterio de laboralidad idóneo para brindar una solución a la cuestión planteada se ha ponderado la dependencia económica como criterio del contrato de trabajo en sustitución de la dependencia jurídica, lo cual, "simplificaría la legislación laboral, al mismo tiempo que permitiría indexar el grado de protección del trabajador a su dependencia"73.

En tal sentido se ha dicho también que la "tendencia a romper la hegemonía de la dependencia jurídica a favor de la dependencia económica ha adquirido vigor en la actualidad, en donde los cambios en la forma de contratación del trabajo ajeno se ha modificado de una manera drástica, dejando numerosas actividades que antes se llevaban a cabo bajo el molde de la dependencia jurídica fuera de sus límites"74.

Sin embargo, consideramos nosotros, la ponderación de la dependencia económica como elemento principal del contrato podría llevarnos al peligro de enmarcar la relación de trabajo humano en nuevas categorías jurídico conceptuales que establezcan únicamente derechos mínimos para quienes prestan sus tareas en tales contextos (v.gr: el TRADE en España), sin poder alcanzar los trabajadores en dichos casos la intensidad de tutela que, entendemos, deberían gozar en la prestación de su labor.

Entre otras propuestas de solución al problema señalado también se han planteado: 1. la tutela de las formas atípicas de labor o prestación de servicios a través de reformas en los Códigos Civiles; 2. la autotutela de colectivos de trabajadores mediante la negociacion colectiva; 3 . la autotutela del trabajador mediante el contrato individual del trabajo; 4 . la protección a través del dictado de leyes especiales que regulen cada una de las actividades en donde se desempeñen trabajadores vulnerables con una marcada dependencia

\footnotetext{
70 Por ejemplo, en el art. 1ro del Estatuto de los Trabajadores Españoles que establece: "La presente ley será de aplicación a los trabajadores que voluntariamente presten sus servicios retribuidos por cuenta ajena y dentro del ámbito de organización y dirección de otra persona, física o jurídica denominada empleador o empresario".

71 TUSET DEL PINO, Pedro, Elementos característicos de la relación de trabajo y su diferenciación con los trabajadores autónomos conforme la legislación laboral española, en Revista Erreius de Abril 2020, en Temas de Derecho Laboral y de la Seguridad Social, Director: TOSELLI, Carlos A.

$72 \mathrm{Al}$ respecto véase TOSELLI, Carlos A, Ajenidad en el contrato de trabajo, en Estudios Críticos de Derecho del Trabajo, editado por la Asociación de Abogados Laboralistas - Editorial Legis - Buenos Aires, 2014, p. 177 179.

73 SUPIOT, Alain, El debate sobre la reforma del Código de Trabajo Francés: Cuando el derecho laboral es un "obstáculo", en Le Monde Diplomatique, Edición número 220, octubre de 2017, accedido el 05/12/17 del sitio web http://www.eldiplo.org/archivo/220-la-ideologia-de-la-represion/cuando-elderecho-laboral-es-un-obstaculo?token $=\& \mathrm{nID}=1$

74 CANDAL, Pablo, Ley de Contrato de Trabajo Comentada, Director: ACKERMAN, Mario E., Coordinadora: SFORSINI, María Isabel, Tomo I, Arts. 1 al 102, Editorial Rubinzal Culzoni, Buenos Aires, Argentina, Año 2016, Pág. 293.
} 
económica; 5. un cambio en el tipo legal de contrato de trabajo por el de un contrato de actividad; 6. y como vimos, la primacía del concepto de dependencia económica por sobre el de dependencia jurídica, sobre todo en el marco de las redes de empresas, otorgado mayor protagonismo a la coordinación que a la idea de subordinación jurídica, y destacando el elemento de ajenidad como nota de la relación de trabajo ${ }^{75}$.

Por su parte, la jurisprudencia de otros paises ha recurrido a diversos indicadores de laboralidad ${ }^{76}$ dentro de los cuales podemos destacar tres, que han sido fundamentales a la hora de brindar tutela al trabajador atípico. Ellos son: 1. en la integración del trabajador en la organización de la empresa; 2. en la imposición de condiciones o reglas por parte de la empresa, y 3 . en el control sobre la prestación de servicios.

Partiendo de dicha base, consideramos que los indicadores de laboralidad que más se ajustan a los fines de la existencia o no de relación laboral entre las partes de un determinado contrato en el marco de una relación atípica de labor, son los establecidos en los diferentes "test" utilizados en Estados Unidos tanto por los diferentes organismos estatales como por los distintos Tribunales. ${ }^{77}$

Entre los mencionados tests ${ }^{78}$, se destaca el "Test del control", que consiste principalmente en determinar si existe control o supervisión por parte de la empresa sobre la forma de ejecución de las tareas o del desarrollo de la actividad de la persona que presta sus servicios, y se complementa con la constatación de los siguientes indicadores: 1. si la actividad del trabajador integra el negocio del empresario (al igual que se establece en la Recomendación $\mathrm{N}^{\circ} 198$ de la OIT), 2. si las tareas o actividad del trabajador requiere de habilidades especiales, caso en el cual podríamos acercarnos más a un trabajo autónomo que a una relación de trabajo dependiente, 3. si el trabajador puede obtener mayores ganancias dependiendo de su habilidad para la realización del trabajo, lo que de no suceder, llevaría a que nos inclinemos por una relación de trabajo en detrimento de un contrato de locación de servicios, 4. la duración de la relación (mientras mayor duración

\footnotetext{
$75 \mathrm{~A}$ los fines de indagar sobre las diferentes propuestas de solución véase: CANDAL, Pablo, Ley de Contrato de Trabajo Comentada, Director: ACKERMAN, Mario E., Coordinadora: SFORSINI, María Isabel, Tomo I, Arts. 1 al 102, Editorial Rubinzal Culzoni, Buenos Aires, Argentina, Año 2016, Pág. 302 y ss. El autor propone la $\mathrm{N}^{\circ} 6$

76 Entre tales argumentos podemos destacar que: 1 el trabajo generalmente es llevado a cabo en forma personal, 2. existe un control del trabajo a través de métricas que miden el rendimiento laboral (algoritmo previamente programado por humanos) y calificaciones de los usuarios, 3. existe una uutilización de vestimenta o equipo identificado con imagen de la empresa, 4. la empresa es quien provee las herramienta de trabajo (cajas, teléfono: Uber), 5. la capacitación de los trabajadores es llevada a cabo por parte de la empresa, 6. el sitio web y las aplicaciones utilizadas por trabajadores son propiedad de la empresa, 7. la empresa es la que fija las tarifas que paga el cliente, 8. la empresa fija unilateralmente la retribución que percibe el trabajador, 9. los pasajeros pagan la tarifa a la empresa y ésta transfiere a los conductores el importe por el servicio prestado, 10. la empresa fija los cronogramas de pagos del trabajador, 11. la empresa admite o no al trabajador aspirante a ingresar al negocio (más estricto en el caso de Uber: antecedentes pers, multas, cuentas bancarias, etc.), 12. la empresa aprueba los vehículos según condiciones tales como antigüedad (no inferior a diez años) y adecuado funcionamiento (Uber), 13. la empresa es quien capta los clientes, 14. no se requiere un alto grado de destreza o formación para trabajar que puedan incrementar ganancias o pérdidas, 15. el trabajador no tiene poder de negociación de las condiciones, 16. los trabajadores deben respetar un código de conducta, v.gr.: debe cuidar sus comentarios en redes sociales (Uber, caso Silva), 16. el trabajador no invierte en su negocio salvo por su trabajo, 17. la empresa publicita a los conductores como "nuestros conductores", 18. la empresa garantiza la calidad del servicio prestado por el trabajador, 19. la empresa puede sancionar al trabajador, suspenderlo o bloquearlo: por baja calificación, por incumplimiento de entrega, por retardo en la entrega, por no trabajar 180 días al año (Uber), 20. no existe relación jurídica entre el trabajador y el clientes o el restaurante, por lo que no se trata un prestador de servicios independiente, 21. existe ausencia de libertad en la determinación de la jornada de trabajo. Dicha libertad sólo se da en el mundo del marketing de estas empresas. El funcionamiento del sistema lleva a que, para mantener un alto rango, el trabajador tenga que realizar un cierto número de entregas, trabajar un número mínimo de turnos en una semana y trabajar un número de viernes, sábados o domingos por la noche.

77 Sin dudas resulta extraño sostener que del ordenamiento jurídico de la legislación de un país caracterizada por la desprotección del trabajador surjan los indicadores de laboralidad que más se adaptan para brindar tutela a quien desarrolla sus tareas en el marco de una relación de trabajo atípica. Sin embargo, lo que sucede en realidad es que si bien en dicha legislación no existe una significativa intensidad en la tutela del trabajador (sobre todo en lo que protección contra el despido arbitrario se refiere), ello no quita a que sus normas se encuentren orientadas a la abarcabilidad y regulación de las diferentes relaciones laborales, que es lo que aquí nos interesa.
}

78 Algunos organismos estatales utilizan el Test de realidades económicas. V.gr: Departament of Labor (DOL): Lo hace teniendo en cuenta 6 factores a los fines de determinar la existencia de relación de trabajo subordinada. 
tenga, más cerca de una relación de trabajo nos encontraremos), 5. el grado de estabilidad del vínculo (mientras mayor estabilidad tenga, también más cerca de una relación de trabajo nos encontraremos), 6. la posibilidad del empresario de extinguir el vínculo unilateralmente y sin causa, lo cual revela un poder de negociación asimétrico, típico del vínculo laboral, 7. si el trabajador se encuentra facultado para contratar ayudantes, extremo que se acreditarse podría, salvo caso de fraude, alejarnos de una relación de trabajo, 8. la constatación de inversión por parte del trabajador en publicidad, oficinas y demás cuestiones necesarias para la realización de un servicio independiente, 9. si en la localidad o en un contexto geográfico determinado el trabajo generalmente se ha realizado en relación de dependencia, lo seguirá siendo más allá de las nuevas formas o metodologías de realización79; 10. la determinación del lugar de trabajo (si el trabajo se realiza en un área o una ruta determinada por el empleador, se infiere el estatus de trabajador dependiente), entre otros. ${ }^{80}$

Cabe agregar que el citado test fue superado por otro denominado "ABT test" que, similar a la mecánica de nuestro art. 23 de la LCT, parte de la presunción de existencia de relación de trabajo entre quien presta sus servicios y el empresario, con la consecuente carga de éste último de desvirtuar dicha presunción, pero sólo mediante la acreditación tres rasgos en forma concurrente: a. ausencia de control y dirección sobre la ejecución del trabajo; b. independencia entre el trabajo ejecutado y la actividad habitual del contratante; y c. precedentes empresariales del prestador del servicio. ${ }^{81}$

Por último, cabe señalar que algunos de los citados tests han tenido recepción, aunque con algunas modificaciones, en algunos países latinoamericanos. ${ }^{82}$

\section{La protección del trabajo con independencia de su forma de realización y la consiguiente desaparición de los límites entre la relación de trabajo dependiente y el contrato de servicios}

Si bien la renovación de los indicadores de laboralidad puede constituir un paso adelante hacia la tutela de los trabajadores que llevan a cabo sus labores o desarrollan su actividad en el marco de relaciones atípicas de labor en detrimento del contrato de servicios, consideramos que un paso superador respecto de este podría ser el tutelar al trabajador atípico, más allá de la forma (dependiente o autónoma) de realización de sus tareas o desarrollo de su actividad.

Al respecto podemos señalar que, si bien cuando se pensó y construyó el Derecho del Trabajo se hizo con la finalidad de brindar tutela sólo al trabajador subordinado o dependiente, en realidad, los diferentes Instrumentos Internacionales ${ }^{83}$ así como también algunas normas de derecho interno ${ }^{84}$, no se encuentran orientados a proteger exclusivamente dicha formas de labor, sino que protegen el derecho al trabajo sin diferenciar su forma de realización (dependiente o autónoma).

\footnotetext{
79 A modo de ejemplo, si el reparto de alimentos a domicilio (delivery) se ha realizado siempre en relación de dependencia, debe seguir siendo de dicho modo más allá de que ahora se lleve a cabo a través de plataformas digitales.

80 BERVEJILlO BENEDETTI, Mateo, Trabajadores de Uber: ¿Relación de dependencia? en https://www.cade.com.uy/trabajadores-uber-relaciondependencia/, extraído el 24/11/18

81 CARBALLO MENA, Cesar Agusto, Vestigios del trabajo dependiente a propósito del escrutinio judicial de Uber Tecnologies Inc. y Dynamex Operations Inc., extraído de file:///D:/USUARIO/Downloads/13142-16887-2-PB\%20(1).pdf

82 V.gr: En Venezuela se utiliza un test donde se constatan los primeros 5 indicios de la Recomendación 198 OIT, y otros cinco restantes fueron establecidos por la Sala de Casación Social del Tribunal Supremo de Justicia de dicho país

83 A modo de ejemplo la Declaración Universal de los Derechos Humanos (art. 23) y el PIDESC (art. 6to) no tutela el trabajo subordinado, sino el trabajo, similar a lo que ocurre con otros Tratados, Pactos y Convenios Internacionales.

84 V.gr: art 14 bis Constitución Nacional Argentina, protege el trabajo "en sus diversas formas".
} 
Pero además, otros Instrumentos Internacionales, tales como por ejemplo el párrafo 6to de la Observación General N 18 del PIDESC ${ }^{85}$, la Observación General No 23 del año 2016 sobre el derecho a condiciones de trabajo equitativas y satisfactorias del Comité de derechos económicos, sociales y culturales ${ }^{86}$, la Recomendación 204 de OIT sobre "La Transición de la economía informal a la economía formal" ${ }^{187}$ y/o la Recomendación Nº 198 de la OIT $^{88}$, entre otros ${ }^{89}$, establecen expresamente la necesidad de protección de trabajo más allá de su forma de realización.

Y si bien en alguna oportunidad ${ }^{90}$ hemos señalado que la tutela del trabajo es necesaria en el marco de cualquier forma de labor (autónoma, autogestionaria, cooperativa, de la economía social o popular, etc.), y que ello resultaría más necesario mientras más vulnerable sea el trabajador o más precarias sus condiciones de trabajo, cabe señalar que en algunas de las formas de labor señaladas se presentarían ciertas dificultades $u$ obstáculos que habría que superar para poder brindar tutela a los trabajadores que se desempeñen en tales marcos, principalmente por la dificultad de identificar a la parte con la cual el trabajador debe negociar sus condiciones de trabajo.

Sin embargo, en las formas de trabajo atípicas signadas por el impacto de la tecnología o en los contratos de servicios con prestadores hiposuficientes, dicha dificultad no se presentaría debido a que, al igual que sucede en la relación de trabajo típica dependiente, existen dos partes bien definidas: una, el dador de trabajo, y otra, quien presta sus servicios, encontrándose ambas partes perfectamente determinadas, con intereses contrapuestos y en planos de jerarquía negocial diferentes, lo que podría dar lugar a una normativa que regule dichas relaciones más allá de la existencia de dependencia o no entre las partes.

\footnotetext{
85 El citado instrumento establece que el "derecho al trabajo engloba todo tipo de trabajos, ya sean autónomos o sujetos dependientes de un salario". El trabajo es digno de reconocimiento social en sus diferentes formas..."

86 Dicha Observación establece que "el Comité es consciente de que los conceptos de trabajo y trabajador han evolucionado desde el momento en que se redactó el pacto y actualmente abarcan nuevas categorías como las de los trabajadores por cuenta propia, los trabajadores del sector informal, los trabajadores agrícolas, os trabajadores refugiados y los trabajadores no remunerados". Es que tal como se ha dicho, "...los derechos humanos laborales, sus fuentes constitucionales y supranacionales, amparan al trabajador como ciudadano portador de derechos humanos subjetivos, pero no circunscriben su radio de actuación a un trabajador que ingresa a un trabajo dependiente formal o informal, estable o precario, sino que comprende al trabajador en su condición de tal, cualquiera sea la forma de su situación legal o real; dependiente o desempleado, en negro, autónomo, cuentapropista, cooperativista o integrante de otras empresas o estructuras que no implican nexo dependiente". Véase en ARESE CESAR, Trabajadores precarios y de economía popular: sindicalización, negociación y conflictos, en Revista de Derecho Laboral Actualidad, 2017-2, Editorial Rubinzal Culzoni, Director: MACHADO, José Daniel, Subdirector: ARESE, Cesar, Bs As, Argentina. Pág. 276 y 277.

87 En el informe presentado en dicha oportunidad se destacó que las normas de OIT no se circunscriben a la economía formal, donde existe una relación clara entre empleador y trabajador, sino que pueden extenderse a otras categorías de trabajadores que en ocasiones, prestan sus tareas o desarrollan sus actividades en el marco de la economía informal. Informe V (1) de OIT, La Transición de la economía informal a la economía formal, Informe realizado con miras a la Conferencia Internacional del Trabajo, $103^{\circ}$ reunión 2014, llevada a cabo con vistas a la realización de una Recomendación (que posteriormente fuera la Recomendación $N^{\circ}$ 204), quinto punto del orden del día, Ginebra, Suiza, año 2013, ISBN 978-92-2-327754-3 (impreso), ISBN 978-92-2-327755-0 (web pdf), ISSN 0251-3226.

88 La citada Recomendación del año 2006 sobre la relación de trabajo establece la tutela efectiva de "los trabajadores especialmente afectados por la incertidumbre en cuanto a la existencia de una relación de trabajo... así como a los trabajadores más vulnerables... los trabajadores de la economía informal, los trabajadores migrantes...”.

89 Resolución del Parlamento Europeo de fecha 15 de junio de 2017 en el marco de la Agenda Europea para la economía colaborativa.

90 Véase CHERCOLES, Ricardo León, La protección del trabajador autónomo vulnerable, en Revista de Derecho Laboral Actualidad, 2017-2, Editorial Rubinzal Culzoni, Director: José Daniel Machado, Subdirector: Cesar Arese, Bs As, Argentina. Pág. 235 a 251.
} 


\section{Referencias Bibliográficas}

- AAVV, Nuevas Tecnologías, presente y futuro del Derecho del Trabajo, Director ARESE, Cesar, Coordinadores: CHÉRCOLES, Ricardo León y FERRARIO, María de los Ángeles, Editorial Rubinzal Culzoni, Año 2019.

- ARESE, Cesar, Código Civil y Comercial y Derecho del Trabajo, con algunos capítulos de autoría de MACHADO, José Daniel, Editorial Rubinzal Culzoni, Santa Fe, Argentina, año 2017.

- ARESE Cesar. Derechos Humanos Laborales. Teoría y práctica de un nuevo derecho del trabajo. Prólogo de BYLOS, Antonio. Editorial Rubinzal-Culzoni. Santa Fe, Argentina. Año 2014

- ARESE CESAR, Trabajadores precarios y de economía popular: sindicalización, negociación y conflictos", en Revista de Derecho Laboral Actualidad, 2017-2, Editorial Rubinzal Culzoni, Director: MACHADO, Jose Daniel, Subdirector: ARESE, Cesar, Bs As, Argentina.

- BERVEJILLO BENEDETTI, Mateo, "Trabajadores de Uber: ¿Relación de dependencia?. Publicado en la web https://www.cade.com.uy/trabajadores-uber-relacion-dependencia/, extraído el 24/11/18

- CANDAL, Pablo, Ley de Contrato de Trabajo Comentada, Director: ACKERMAN, Mario E., Coordinadora: SFORSINI, María Isabel, Tomo I, Arts. 1 al 102, Editorial Rubinzal Culzoni, Buenos Aires, Argentina, Año 2016

- CARBALlO MENA, Cesar Agusto, Vestigios del trabajo dependiente a propósito del escrutinio judicial de UberTecnologies Inc. y DynamexOperations Inc., extraido de file:///D:/ USUARIO/Downloads/13142-16887-2-PB\%20(1).pdf

- CHERCOLES, Ricardo León, La protección del trabajador autónomo vulnerable, en Revista de Derecho Laboral Actualidad, 2017-2, Editorial Rubinzal Culzoni, Director: MACHADO, José Daniel, Subdirector: ARESE, Cesar, Bs As, Argentina

- DUARTE, David, La Relación de Trabajo, en Jurisprudencia laboral de la Corte Suprema Justicia de la Nación comentada, Director: ACKERMAN, Mario E., Coordinadora: SFORSINI, María Isabel, Tomo I, Editorial: Rubinzal Culzoni, Santa Fe, Año 2019, Pág. 39 y 40

- ELIAS, Jorge, Hiposuficiencia reclamacional, un nuevo desafío para el derecho del trabajo, En Revista Derecho del Trabajo. Thomson Reuters - La Ley, Buenos Aires,

- FERNANDEZ BARREDO, Ramiro. Código Civil y Comercial de la Nación, Comentado y Concordado. Tomo II (artículos 957 a 1707), Director VITOLO, Daniel Roque, Prologo de KEMELMAJER DE CARLUCCl, Aida, Editorial Erreius, Buenos Aires, 2015.

- FORMARO, Juan J, "El contrato de servicios y el contrato de trabajo", en Código Civil y Comercial de la Nación y normas complementarias - Análisis doctrinal y jurisprudencial, $3 \mathrm{D}$, Artículos 1227 - 1452 Derechos Personales, Director: BUERES, Alberto J., Coordinadores: COMPAGNICCI DE CASO, Rubén H y GEBHARDT, Marcelo, Editorial Hammurabi - José Luis Depalma, 1 ra edición, Buenos Aires, Argentina, año 2018, ISBN 978-950-741-912-6

- GREGORINI CLUSELLAS, Eduardo y GREGORINI Leonardo R, El contrato de servicios y el contrato de trabajo, en Código Civil y Comercial de la Nación y normas complementarias - Análisis doctrinal y jurisprudencial, 3 D, Artículos 1227 - 1452 Derechos Personales, Director: BUERES, Alberto J., Coordinadores: COMPAGNICCI DE CASO, Rubén H y GEBHARDT, Marcelo, Editorial Hammurabi - José Luis Depalma, 1ra edición, Buenos Aires, Argentina, año 2018, ISBN 978-950-741-912-6

- HERNANDEZ Carlos A., Código Civil y Comercial de la Nación Comentado, Director: LORENZETTI, Ricardo Luis, Coordinadores: DE LORENZO, Miguel Federico y LORENZETTI, Pablo, Tomo VI (Arts. 1021 a 1279), Editorial Rubinzal - Culzoni, Santa Fe, Argentina, Año 2015, (edición encuadernada)

- LEIVA FERNANDEZ, Luis F. P., Código Civil y Comercial Comentado, Tratado Exegético, Di- 
rector General: ALTERINI, Jorge Horacio, Directores del Tomo: ALCEGA, María Valentina, GOMEZ LEO, Osvaldo R. y LEIVA FERNANDEZ, Luis F.P, Coordinador: ALTERINI, Ignacio E, Tomo VI (Arts. 1123 a 1377), Editorial Thomson Reuters - La Ley, Buenos Aires, Argentina, Año 2015, ISBN 978-987-03-2925-1.

- PEREZ CRESPO, Guillermo E., El nuevo Código Civil y Comercial y su incidencia en la corrosión del Derecho del Trabajo. El caso particular de los contratos de suministro, obra y servicios, en Derecho del Trabajo, un estudio sobre las implicancias del nuevo Código Civil y Comercial desde una perspectiva crítica, Coordinador: DUARTE, David, Editorial B de F Ltda., 2016, ISBN: 978-9974-745-03-2

- SUPIOT, Alain. El debate sobre la reforma del Código de Trabajo Francés: Cuando el derecho laboral es un "obstáculo", Publicado en Le Monde Diplomatique, Edición número 220, octubre de 2017, accedido el 05/12/17 del sitio web http://www.eldiplo.org/archivo/220la-ideologia-de-la-represion/cuando-el-derecho-laboral-es-un-obstaculo?token=\&nID=1 - TOSELLI, Carlos A, Ajenidad en el contrato de trabajo, en Estudios Críticos de Derecho del Trabajo, editado por la Asociación de Abogados Laboralistas - Editorial Legis - Buenos Aires, 2.014

- TUSET DEL PINO, Pedro, Elementos característicos de la relación de trabajo y su diferenciación con los trabajadores autónomos conforme la legislación laboral española. En Revista Erreius de Abril 2020, en Temas de Derecho Laboral y de la Seguridad Social, Director: TOSELLI, Carlos A. 